\title{
Molecular and computational analysis of 45 samples with a serologic weak $D$ phenotype detected among 132,479 blood donors in northeast China
}

Xu Zhang ${ }^{1,2+} \odot$, Guiji Li ${ }^{3 \dagger}$, Zhuren Zhou ${ }^{1,2}$, Chaopeng Shao ${ }^{4}$, Xuying Huang ${ }^{1,2}$, Lichun Li ${ }^{1,2}$, Xiaofeng Li ${ }^{1,2}$, Ying Liu ${ }^{5}$, Hua Fan ${ }^{3^{*}}$ and Jianping Li $i^{1,2,5,6^{*}}$

\begin{abstract}
Background: $\mathrm{RH} 1$ is one of the most clinically important blood group antigens in the field of transfusion and in the prevention of fetal incompatibility. The molecular analysis and characterization of serologic weak $D$ phenotypes is essential to ensuring transfusion safety.

Methods: Blood samples from a northeastern Chinese population were randomly screened for a serologic weak $D$ phenotype. The nucleotide sequences of all 10 exons, adjacent flanking intronic regions, and partial $5^{\prime}$ and $3^{\prime}$ untranslated regions (UTRs) were detected for RHD genes. Predicted deleterious structural changes in missense mutations of serologicl weak D phenotypes were analyzed using SIFT, PROVEAN and PolyPhen2 software. The protein structure of serologic weak D phenotypes was predicted using Swiss-PdbViewer 4.0.1.

Results: A serologic weak D phenotype was found in 45 individuals (0.03\%) among 132,479 blood donors. Seventeen distinct $R H D$ mutation alleles were detected, with 11 weak $D$, four partial $D$ and two DEL alleles. Further analyses resulted in the identification of two novel alleles (RHD weak D 1102A and 399C). The prediction of a three-dimensional structure showed that the protein conformation was disrupted in 16 serologic weak D phenotypes.
\end{abstract}

Conclusions: Two novel and 15 rare RHD alleles were identified. Weak D type 15, DVI Type 3, and RHD1227A were the most prevalent $D$ variant alleles in a northeastern Chinese population. Although the frequencies of the $D$ variant alleles presented herein were low, their phenotypic and genotypic descriptions add to the repertoire of reported RHD alleles. Bioinformatics analysis on RhD protein can give us more interpretation of missense variants of RHD gene.

Keywords: RHD variant, Serological weak D phenotype, Molecular and computational analysis, Weak D, Partial D, DEL

\section{Background}

The number of blood group antigens currently recognized by the International Society of Blood Transfusion is 360, and 322 of them are clustered within 36 blood group systems [1]. The Rh blood group system is the most complex

\footnotetext{
*Correspondence: fanhua66cn@163.com; ljp_63@163.com

${ }^{\dagger}$ Xu Zhang and Guiji Li contributed equally in this work

1 Institute of Transfusion Medicine, Liaoning Blood Center, Shenyang,

Liaoning, China

${ }^{3}$ Department of Hematology, The Forth Affiliated Hospital of China

Medical University, Shenyang, Liaoning, China

Full list of author information is available at the end of the article
}

among all blood group systems [2]. The D (RH1) antigen is the most immunogenic and clinically significant antigen, which directly affects the hemolytic transfusion reaction and hemolytic diseases of fetuses and newborns [2, 3]. Besides D-positive and D-negative, $\mathrm{RhD}$ blood groups have multiple variants, including weak $\mathrm{D}$, partial $\mathrm{D}$ and $\mathrm{DEL}$ phenotype [4]. A Working Group of the American Association of Blood Banks and College of American Pathologists published a proposal to use the term "serologic weak D phenotype" to distinguish the results of serological weak $\mathrm{D}$ testing using anti-human globulin with those of weak $\mathrm{D}$ genotyping based on molecular methods $[5,6]$. 
The genetic alterations of $R H D$ alleles differentially influence the RhD protein expression level and the number of RhD epitopes [7]. Weak D and most DEL have all D epitopes; partial D lack one or more D epitopes [3]. Anti-D production in $\mathrm{RhD}$ negative recipients transfused with blood from weak $\mathrm{D}$, particle $\mathrm{D}$ and DEL donors has been reported [8-11]. Therefore, it is of great significance to accurately determine a serologic weak $\mathrm{D}$ phenotype. Nearly all serologic weak D phenotypes can be traced back to changes at the DNA level, including nonsense mutations, missense and synonymous mutations, frame shifts, unequal exchange, gene exchange and gene deletion, as well as others. This enables us to study the molecular mechanism of a serologic weak D phenotype at the gene level, and to determine the type of serologic weak $\mathrm{D}$ phenotype.

To date, more than $460 R H D$ alleles have been registered and nominated [12-14]. Serologic weak D phenotypes are often found in the blood samples of blood donors and patients, and molecular studies have been mainly conducted in Caucasian and African populations [15-23]. Corresponding research on the diversity of serologic weak D phenotypes has been reported in southern [24-28], but rarely in northeastern populations in China. Herein, we tested samples from a cohort of 132,479 blood donors in northeastern China for the serologic weak D phenotype. We subsequently sequenced the $R H D$ gene of the 45 samples identified in this study as showing a serologic weak D phenotype. We built and optimized threedimensional (3D) models of serologic weak $\mathrm{D}$ phenotypes identified in this study to explore their effect on $\mathrm{RhD}$ protein structure. Bioinformatics tools were employed to provide computational predictions on the $\mathrm{RhD}$ protein structure of serologic weak D phenotypes and enhance our understanding of how mutations affect phenotypes at the same time.

\section{Materials and methods}

\section{Study participants}

All 132,479 samples were collected from blood donors at the Blood Center of Liaoning Province, which is located in northeastern China, over a 5 -year period (January 2012 to December 2016). Some donors may have donated repeatedly, which is common in similar large studies of the past and is known not to affect the statistics and conclusions. The study was approved by the Ethics Committee of the Liaoning Blood Center, Liaoning, China.

\section{Serological studies}

The D antigen was serologically determined using a monoclonal anti-D reagent (IgM, Clone BS226, Bio-Rad Medical Diagnostics GmbH Industriestrabe, Germany) using a microplate test protocol and a fully automated blood grouping instrument (Hemo-Type automatic blood group analyzer; GSG Robotix, Milan, Italy). For the microplate test protocol and testing in a fully automatic blood grouping instrument, $6 \mu \mathrm{L}$ of whole blood from a sample tube was added to $333 \mu \mathrm{L}$ of $0.9 \%$ saline in a test tube and mixed. An erythrocyte suspension ( 35 $\mu \mathrm{L}$ ) was absorbed to a micropore and mixed with $25 \mu \mathrm{L}$ of anti-D reagent in accordance with the manufacturer's instructions.

We retested all samples showing negative or equivocal agglutination by tube method with three commercially available anti-D reagents (1-IgM/IgG blend, Clone D175-2 and D415 1E4, Dominion Biologicals Ltd., Dartmouth, Nova Scotia, Canada; 2-IgM/IgG blend, Clone P3X61, P3X21223B10, P3X290 and P3X35, Diagast Ltd, Loos, France; 3-IgM/IgG blend, Clone TH-28 and MS-26, Merck Millipore Ltd, Livingston, UK). An indirect antiglobulin test (IAT) was performed in the case of negative reactions. $\mathrm{RhD}$-negative phenotyping was performed for all samples by hemagglutination using two techniques (microtiter plate and tube); samples were not identified by serologic adsorption-elution techniques. We performed an antibody screening test for blood group alloantibodies on all D-negative and serologic weak D phenotype samples using a gel method (DiaMedID, microtyping system, DiaMed China Limited, Hong Kong, China). Routine Rh typing for C, c, E, and e antigens was performed by the tube method with commercial monoclonal immunoglobulin (IgM) reagents (anti-C, Clone MS-24; anti-c, Clone MS-33; anti-E, MS-80 + 258; and anti-e, Clone MS-16+21+63, Shanghai HemoPharmaceutical \& Biological, Inc., Shanghai, China).

\section{Molecular analysis of genomic DNA}

Genomic DNA was extracted from a $0.2 \mathrm{~mL}$ blood sample using a DNA whole blood isolation kit (Tiangen Biotech, Beijing, China) in accordance with the manufacturer's instructions. The RHD gene was sequenced in all serologic weak D phenotypes and $117 \mathrm{D}$ antigen negative samples by IAT as previously described [24]. The nucleotide sequences of all 10 exons as well as adjacent flanking intronic regions, including partial $5^{\prime}$ and $3^{\prime}$ untranslated regions (UTRs), were determined (Table 1). Genomic DNA (50 to $100 \mathrm{ng}$ ) was used in a $25 \mu \mathrm{L}$ reaction mix containing $200 \mathrm{mM}$ dNTPs, $0.1 \mathrm{mM}$ of each specific primer, $1.5 \mathrm{mM} \mathrm{MgCl}_{2}, 1 \times \mathrm{PCR}$ buffer, and 1 unit of GoTaq polymerase (Promega, Madison, WI, USA), supplemented with $d_{d} \mathrm{H}_{2} \mathrm{O}$. The following PCR program was used: 5 min of denaturation at $95^{\circ} \mathrm{C}, 35$ cycles of $30 \mathrm{~s}$ at $94{ }^{\circ} \mathrm{C}, 30 \mathrm{~s}$ at $62{ }^{\circ} \mathrm{C}$ (exons $\left.1,3,4,6-10\right), 30 \mathrm{~s}$ 
Table 1 Primers for RHD gene amplification and sequencing

\begin{tabular}{|c|c|c|c|c|c|}
\hline Primer denotation & Sequence $\left(5^{\prime}\right.$ to $\left.3^{\prime}\right)$ & Specificity & GenBank accession number & Location & $\begin{array}{l}\text { Product } \\
\text { size (bp) }\end{array}$ \\
\hline $\mathrm{E} 1-\mathrm{s}(=\mathrm{E} 1-\mathrm{seq})$ & TCCATAGAGAGGCCAGCACAA & $\mathrm{D}$ & AJ252314 & $5^{\prime}$ UTR -152 to -132 & 340 \\
\hline E1-a & GCTATTTGCTCCTGTGACCACTT & D & Z97363 & +40 to +18 & \\
\hline E2-s & TGACGAGTGAAACTCTATCTCGAT & $\mathrm{D}$ & U66341 & -1060 to -1037 & 1602 \\
\hline $\mathrm{E} 2-\mathrm{a}$ & GGCATGTCTATTTCTCTCTGTCTAAT & $\mathrm{D} / \mathrm{CE}$ & U66341, AB035189 & +355 to +330 & \\
\hline E2-seq & CCTGGATTCCTTGTGATACACG & $\mathrm{D} / \mathrm{CE}$ & U66341, U66340 & +227 to +206 & \\
\hline E3-s & GTCGTCCTGGCTCTCCCTCTCT & $\mathrm{D}$ & AB035190 & -29 to -8 & 219 \\
\hline E3-a & СTTTTCTCCCAGGTCCCTCCT & $\mathrm{D} / \mathrm{CE}$ & AB035192, AB035191 & +39 to +19 & \\
\hline E3-seq & GGTCCCTCCTCCCAGCAC & $\mathrm{D} / \mathrm{CE}$ & AB035192, AB035191 & +28 to +11 & \\
\hline E4-s & GCCGACACTCACTGCTCTTAC & $\mathrm{D} / \mathrm{CE}$ & U77079, U77078 & -36 to -16 & 378 \\
\hline E4-a & TGAACCTGCTCTGTGAAGTGC & $\mathrm{D}$ & Y10605 & +194 to +174 & \\
\hline E4-seq & GGGAGATTTTTTTCAGCCAG & $\mathrm{D} / \mathrm{CE}$ & Y10605, Y10604 & +82 to +64 & \\
\hline E5-s & TACCTTTGAATTAAGCACTTCACAG & $\mathrm{D}$ & Y10605 & -267 to -243 & 1458 \\
\hline E5-a & TTATTGGCTACTTGGTGCC & $\mathrm{D} / \mathrm{CE}$ & Z97334, AB035197 & +1024 to +1006 & \\
\hline E5-seq & AGACCTTTGGAGCAGGAGTG & $\mathrm{D} / \mathrm{CE}$ & Y10605, Y10604 & -53 to -34 & \\
\hline $\mathrm{E} 6-\mathrm{s}(=\mathrm{E} 6-\mathrm{seq})$ & CAGGGTTGCCTTGTTCCCA & $\mathrm{D} / \mathrm{CE}$ & Z97334, Z97333 & -95 to -97 & 274 \\
\hline E6-a & CTTCAGCCAAAGCAGAGGAGG & $\mathrm{D}$ & Z97334 & +41 to +21 & \\
\hline E7-s & TGCCCATCCCCCTTTGGTGGCC & $\mathrm{D}$ & Z97334 & -106 to -85 & 411 \\
\hline E7-a & CCAAGGTAGGGGCTGGACAG & $\mathrm{D}$ & AB035194 & +171 to +152 & \\
\hline E7-seq & GTCTCACCTGCCAATCTGCT & $\mathrm{D} / \mathrm{CE}$ & Z97334, Z97333 & -41 to -22 & \\
\hline E8-s & GGTCAGGAGTTCGAGATCAC & $\mathrm{D}$ & AB035194 & -593 to -574 & 770 \\
\hline $\mathrm{E} 8-\mathrm{a}(=\mathrm{E} 8-\mathrm{seq})$ & GATGGGGCACATAGACATCC & $\mathrm{D} / \mathrm{CE}$ & AB035196 & +97 to +78 & \\
\hline E9-s(=E9-seq) & GGTCCAGGAATGACAGGGCT & $\mathrm{D}$ & AB035196 & -162 to -143 & 530 \\
\hline E9-a & CGCTGAGGACTGCAGATAGG & $\mathrm{D}$ & AB035185 & +294 to +275 & \\
\hline E10-s & CAAGAGATCAAGCCAAAATCAGT & $\mathrm{D} / \mathrm{CE}$ & AB035185, AB035184 & -67 to -45 & 381 \\
\hline E10-a & AGCTTACTGGATGACCACCA & $\mathrm{D}$ & X63097 & +290 to +271 & \\
\hline E10-seq & CAGTCTGTTGTTTACCAGATGTTGTTAT & $\mathrm{D}$ & X63097 & $3^{\prime} \mathrm{UTR}+261$ to +234 & \\
\hline
\end{tabular}

Primers cited from [24]

$s$ sense primer, $a$ antisense primer, seq sequencing primer

at $58{ }^{\circ} \mathrm{C}$ (exons 2,5 ), and $1 \mathrm{~min}$ at $72{ }^{\circ} \mathrm{C}$, followed by a final 10-min extension at $72{ }^{\circ} \mathrm{C}$. The PCR procedure was carried out in a PE-9700 thermal cycler (Applied Biosystems, Foster City, CA, USA). Sequencing data were analyzed with FinchTV software (Geospiza Inc., Seattle, WA, USA) and all results compared to a NCBI Reference Sequence (RefSeq) database number NG_007494.1. The amino acid alignment of RhD was analyzed by CLUSTAL $\mathrm{X}$ (version 2.1) and the amino acid sequences used in the analysis were obtained from a protein database (https ://www.ncbi.nlm.nih.gov/protein). RHD zygosity was determined on all sequencing samples by the presence or absence of a hybrid Rhesus box as described [29].

\section{Statistical analysis}

Allele frequencies were calculated from corresponding genotype counts. According to Hardy-Weinberg equilibrium, genotype frequency of D negative homozygote is equal to the square of the $\mathrm{D}$ negative allele frequency, and genotype frequency of the heterozygote ( $\mathrm{D}$ variant and $\mathrm{D}$ negative) is equal to twice the product of the two allele frequencies. Allele frequencies for each molecular background of serologic weak D and D negative phenotypes were calculated.

\section{Computational modeling of $\mathrm{RhD}$ protein and amino acid substitutions}

The 3D structure of the RhD protein was visualized using Swiss-Pdb Viewer 4.1.0 (https://spdbv.vital-it.ch/), which was used to generate models of the selected protein structure for the corresponding amino acid substitutions [30, 31]. Sorting Intolerant From Tolerant (SIFT) [32], Polymorphism Phenotyping algorithmV2 (PolyPhen-2) [33] and Protein Variation Effect Analyzer (PROVEAN) [34] software were used to predict the impact of amino acid substitutions on $\mathrm{RhD}$ protein structure. 


\section{Results}

\section{Serological studies}

Using routine methods, we screened 132,479 blood donors for D antigen, 131,939 of whom were found to be $\mathrm{D}+(99.592 \%), 495$ were $\mathrm{D}-(0.374 \%)$, and 45 $(0.034 \%)$ had a serologic weak D phenotype [5]. They were sorted based on the anti-D agglutination strength using the two routine techniques, and were also tested with three monoclonal anti-D reagents. No blood group alloantibody was detected in the plasmas of 45 serologic weak D phenotype samples.

\section{Molecular characterization of $D$ variants}

We determined the RHD sequence of the coding region, adjacent flanking intronic regions, and the partial $5^{\prime}$ and $3^{\prime}$ UTRs in all 45 serologic weak D phenotype samples and detected 17 distinct alleles (Table 2). Twenty-nine individuals were weak D types representing 11 distinct alleles. Twelve individuals were partial D phenotypes representing four distinct alleles. Four individuals were DEL phenotypes representing two distinct alleles. Two novel single-nucleotide missense mutations (c.399G > C and c.1102G > A) were identified in three individuals. The DNA sequences of two novel alleles have been submitted to the GenBank Database (accession numbers KM282169 and KM282170, respectively). Six individuals carried complex alleles: one individual carried weak D 101G (c.101A > G) and weak D type 15 (c.845 G > A) alleles, while another five individuals had a weak D (c.399G > C, c.845 G>A, c.763G > C, c.779A $>$ G, c. $1212 \mathrm{C}>\mathrm{A}$, respectively) and $R H D 1227 \mathrm{~A}$ allele (c.1227G $>\mathrm{A})$. One each of weak $D$ type 72 (c.1212C > A), weak D type 18 (c.19C > T), weak D type 25 (c.341G > A), weak D type 31 (c.17C > T) and weak D type 54 (c.365C > T) were identified.

\section{Calculation of allele frequencies}

In our study, phenotype frequencies of serologic weak D and D negative phenotypes were 0.00034 and 0.00374 , respectively. According to calculation, the $\mathrm{D}$ negative allele frequency was 0.06113 , and frequency of a single D variant allele observation was 0.00005 . In $117 \mathrm{D}$ negative samples, $66.67 \%$ of the genetically tested $\mathrm{RhD}$ negatives seemed to be homozygous for the RHD deletion, and $33.33 \%$ had a deletion of $R H D$ plus a variant $R H D$ or a $R H D-C E-D$ hybrid gene. Cumulative RHD $1227 A$ allele frequency among weak $D$ and $D$ negative phenotypes was 0.00853. Expected homozygous deletion of RHD had a genotype frequency of 0.00244 . Allele frequencies of serologic weak D phenotypes and D negative alleles were calculated as shown in Tables 3 and 4. Raw data for calculation of serologic weak $\mathrm{D}$ and $\mathrm{RhD}$ negative allele frequencies are shown in Additional file 1: Table S1.

\section{Predicted effect of nonsynonymous substitutions}

SIFT, PolyPhen-2, and PROVEAN bioinformatic software programs were used to predict deleterious structural changes induced by nonsynonymous p.P6L, p.R7W, p.R10W, p.Y34C, p.R114Q, p.S122L, p.K133N, p.G255R, H260R, p.G282D, p.G368R, and p.D404E substitutions (Additional file 2: Table S2). The 12 nonsynonymous substitutions were distributed along the whole length of the RHD coding sequence without any apparent clustering (Fig. 1) [4, 45].

\section{Bioinformatics analysis of RhD protein structure model}

The template of RhD protein homology model was in accordance with the model based on computational hydropathy map [45, 46]. The model comprised 409 amino acids from Ser3 to Pro411 and lacked nine residues (two in the $\mathrm{N}$ terminus and six in the $\mathrm{C}$ terminus, Additional file 3: Table S3). The RhD 3D protein structures of the wild-type and 16 serologic weak $D$ phenotypes highlighted the change in structure with altered amino acids. A 3D structure analysis of 16 serologic weak D phenotypes predicted amino acid position shifts in intracellular and exofacial loops, and the transmembraneous domain. The 3D structure model also demonstrated that p.P6L, p.R7W, p.R10W, p.Y34C, p.R114Q, p.S122L, p.K133 N, p.G280D, p.G368R and p.D404E mutations led to the disappearance of beta sheets, and position changes due to p.G255R and p.H260R mutations in beta sheets. The 3D structure model of four partial D types displayed the disappearance of beta sheets in DVI type 3 and DV type 2, an increase in beta sheets at amino acids 38-40 and 42-44 in DVI type 4, and no change in beta sheets in DFR type 2 only, with an amino acid position shift in intracellular and exofacial loops, and the transmembraneous domain. The 3D structure model of four partial D types displayed the disappearance of beta sheets in DVI type 3 and $D V$ type 2, an increase in beta sheets at amino acids 38-40 and 42-44 in DVI type 4, and no change in beta sheets in DFR type 2 only, with an amino acid position shift in intracellular and exofacial loops, and the transmembraneous domain (Fig. 2).

\section{Discussion}

In the present study, we investigated the molecular characteristics of serologic weak D phenotypes in a northeastern population in China. The bioinformatics of 17 variant $R H D$ alleles for serologic weak D phenotypes, including two novel alleles, were analyzed. The $R H D$ allele distribution varies widely between Asian [24-28, 47-49] and European centers [15-21]. Differences in populations 
Table 2 RHD alleles found among donors with a serologic weak D phenotype

\begin{tabular}{|c|c|c|c|c|c|c|c|c|c|}
\hline $\begin{array}{l}\text { Sample } \\
\text { number }\end{array}$ & $R H D$ allele & $\begin{array}{l}\text { Occurrence } \\
\text { frequency } \\
(\%)\end{array}$ & $\begin{array}{l}\text { Phenotype } \\
\text { annotation }\end{array}$ & $\begin{array}{l}\text { Nucleotide } \\
\text { change }\end{array}$ & $\begin{array}{l}\text { Amino acid } \\
\text { substitution }\end{array}$ & Haplotype & $\begin{array}{l}\text { Hybrid } \\
\text { Rhesus box } \\
\text { results }\end{array}$ & $\begin{array}{l}\text { ISBT } \\
\text { terminology }\end{array}$ & References \\
\hline $1-16$ & $\begin{array}{l}\text { Weak D type } \\
15\end{array}$ & $16(35.6)$ & Weak D & $c .845 G>A$ & p.G282D & $\begin{array}{l}\text { CDE/CDE/ } \\
\text { CDe }\end{array}$ & $\begin{array}{c}\text { RHD+/ } \\
\text { RHD- }\end{array}$ & $R H D^{*} 15$ & [35] \\
\hline 17 & $\begin{array}{l}\text { Weak D type } \\
15 \\
\text { RHD 1227A }\end{array}$ & $1(2.2)$ & Weak D & $\begin{array}{l}\text { c. } 845 G>A \\
c .1227 G>A\end{array}$ & $\begin{array}{l}\text { p.G282D } \\
\text { p.K409K }\end{array}$ & $\mathrm{CDe}$ & $\begin{array}{c}\text { RHD+/ } \\
\text { RHD+ }\end{array}$ & $\begin{array}{l}\text { RHD*15 } \\
\text { RHD*01EL.01 }\end{array}$ & {$[35,36]$} \\
\hline 18 & $\begin{array}{l}\text { Weak D type } \\
18\end{array}$ & $1(2.2)$ & Weak D & c. $19 C>T$ & p.R7W & CDe & $\begin{array}{c}\text { RHD+/ } \\
\text { RHD- }\end{array}$ & $R H D^{*} 01$ W.18 & {$[37]$} \\
\hline 19 & $\begin{array}{l}\text { Weak D type } \\
25\end{array}$ & $1(2.2)$ & Weak D & c. $341 \mathrm{G}>\mathrm{A}$ & p.R114Q & CDe & $\begin{array}{c}\text { RHD+/ } \\
\text { RHD- }\end{array}$ & RHD*01 W.25 & [38] \\
\hline 20 & $\begin{array}{l}\text { Weak D type } \\
31\end{array}$ & $1(2.2)$ & Weak D & C. $17 \mathrm{C}>\mathrm{T}$ & p.P6L & CDe & $\begin{array}{c}\text { RHD+/ } \\
\text { RHD- }\end{array}$ & RHD*01W.31 & [39] \\
\hline 21 & $\begin{array}{l}\text { Weak D type } \\
54\end{array}$ & $1(2.2)$ & Weak D & c. $365 C>T$ & p.S122L & CDe & $\begin{array}{l}\text { RHD+/ } \\
\text { RHD- }\end{array}$ & $R H D * 01 W .54$ & {$[38]$} \\
\hline 22 & $\begin{array}{l}\text { Weak D type } \\
72\end{array}$ & $1(2.2)$ & Weak D & c. $1212 C>A$ & p.D404E & CDe & $\begin{array}{c}\text { RHD+/ } \\
\text { RHD- }\end{array}$ & RHD*01W.72 & \\
\hline 23 & $\begin{array}{l}\text { Weak D type } \\
\quad 72 \\
\text { RHD 1227A }\end{array}$ & $1(2.2)$ & Weak D & $\begin{array}{l}\text { c. } 1212 C>A \\
\text { c. } 1227 G>A\end{array}$ & $\begin{array}{l}\text { p.D404E } \\
\text { p.K409K }\end{array}$ & CDe & $\begin{array}{l}\text { RHD+/ } \\
\text { RHD+ }\end{array}$ & $\begin{array}{l}\text { RHD*01W.72 } \\
\text { RHD*01EL.01 }\end{array}$ & {$[36]$} \\
\hline 24 & $\begin{array}{l}\text { RHD weak D } \\
\text { 763C } \\
\text { RHD 1227A }\end{array}$ & $1(2.2)$ & Weak D & $\begin{array}{l}\text { C. } 763 G>C \\
\text { c. } 1227 G>A\end{array}$ & $\begin{array}{l}\text { p.G255R } \\
\text { p.K409K }\end{array}$ & CDe & $\begin{array}{c}\text { RHD+/ } \\
\text { RHD+ }\end{array}$ & RHD*01EL.01 & {$[36]$} \\
\hline 25 & $\begin{array}{l}\text { RHD weak D } \\
101 G \\
\text { Weak D type } \\
15\end{array}$ & $1(2.2)$ & Weak D & $\begin{array}{l}c .101 A>G \\
c .845 G>A\end{array}$ & $\begin{array}{l}\text { p.Y34C } \\
\text { p.G282D }\end{array}$ & CDe & $\begin{array}{c}\text { RHD+/ } \\
\text { RHD+ }\end{array}$ & $R H D^{*} 15$ & {$[25,35]$} \\
\hline 26 & $\begin{array}{l}\text { RHD weak D } \\
\text { 399C } \\
\text { RHD 1227A }\end{array}$ & $1(2.2)$ & Weak D & $\begin{array}{l}\text { C. } 399 \mathrm{G}>\mathrm{C} \\
\text { C.1227G > A }\end{array}$ & $\begin{array}{l}\text { p.K133N } \\
\text { p.K409K }\end{array}$ & CDe & $\begin{array}{l}\text { RHD+/ } \\
\text { RHD+ }\end{array}$ & RHD*01EL.01 & {$[36]$} \\
\hline 27 & $\begin{array}{l}\text { RHD weak D } \\
\text { 779G } \\
\text { RHD 1227A }\end{array}$ & $1(2.2)$ & Weak D & $\begin{array}{l}\text { C. } 779 A>G \\
\text { c. } 1227 G>A\end{array}$ & $\begin{array}{l}\text { p.H260R } \\
\text { p.K409K }\end{array}$ & CDE & $\begin{array}{l}\text { RHD+/ } \\
\text { RHD+ }\end{array}$ & RHD*01EL.01 & {$[25,36]$} \\
\hline $28-29$ & $\begin{array}{l}\text { RHD weak D } \\
1102 \mathrm{~A}\end{array}$ & $2(4.4)$ & Weak D & c. $1102 \mathrm{G}>\mathrm{A}$ & p.G368R & CDe & $\begin{array}{c}\text { RHD+/ } \\
\text { RHD- }\end{array}$ & & \\
\hline 30 & $\begin{array}{l}\text { weak D type } \\
61\end{array}$ & $1(2.2)$ & DEL & c. $28 \mathrm{C}>\mathrm{T}$ & p.R10W & CDe & $\begin{array}{l}\text { RHD+/ } \\
\text { RHD- }\end{array}$ & $R H D * 01$ W.61 & {$[40]$} \\
\hline $31-33$ & RHD 1227A & $3(6.7)$ & DEL & c. $1227 G>A$ & p.K409K & $\mathrm{CDe} / \mathrm{CDE}$ & $\begin{array}{c}\text { RHD+/ } \\
\text { RHD- }\end{array}$ & RHD*01EL.01 & {$[36]$} \\
\hline 34 & DFR type2 & $1(2.2)$ & Partial D & \multicolumn{2}{|c|}{ RHD (D1-3 CE4 D5-10) } & CDe & $\begin{array}{c}\text { RHD+/ } \\
\text { RHD- }\end{array}$ & $R H D^{*} 17.02$ & [41] \\
\hline $35-37$ & DV type 2 & $3(6.7)$ & Partial D & \multicolumn{2}{|c|}{ RHD (D1-4CE3-5 D6-10) } & $\mathrm{CDE} / \mathrm{CDE}$ & $\begin{array}{c}\text { RHD+/ } \\
\text { RHD- }\end{array}$ & $R H D^{*} 05.02$ & {$[42]$} \\
\hline $38-44$ & DVI type 3 & $7(15.6)$ & Partial D & \multicolumn{2}{|c|}{ RHD (D1-2-CE3-6-D7-10) } & CDe & $\begin{array}{c}\text { RHD+/ } \\
\text { RHD- }\end{array}$ & $R H D^{*} 06.03$ & [43] \\
\hline 45 & DVI type 4 & $1(2.2)$ & Partial D & \multicolumn{2}{|c|}{ RHD (D1-2 CE3-5 D6-10) } & CDe & $\begin{array}{c}\text { RHD+/ } \\
\text { RHD- }\end{array}$ & $R H D^{*} 06.04$ & [44] \\
\hline
\end{tabular}

ISBT International Society of Blood Transfusion

and routine serologic screening procedures employed, as well as in the molecular examinations used, may account for such differences to date, highlighting the need for standardization. In this study, Weak D type 15, DVI Type 3 and DEL (RHD1227A) were the most prevalent D variant alleles measured in the northeastern Chinese population, which were consistent with those reported in southern Chinese population [24, 25, 27]; however, they were rare in other populations. Therefore, the frequency of distribution of serologic weak D phenotypes varies among populations and ethnic groups.

Our tests detected two mutation types for DEL variants. One type was $R H D 1227 A$ (c.1227G $>\mathrm{A}$ ), and the other was weak D type 61 (c.28C > T). Weak D type 61 


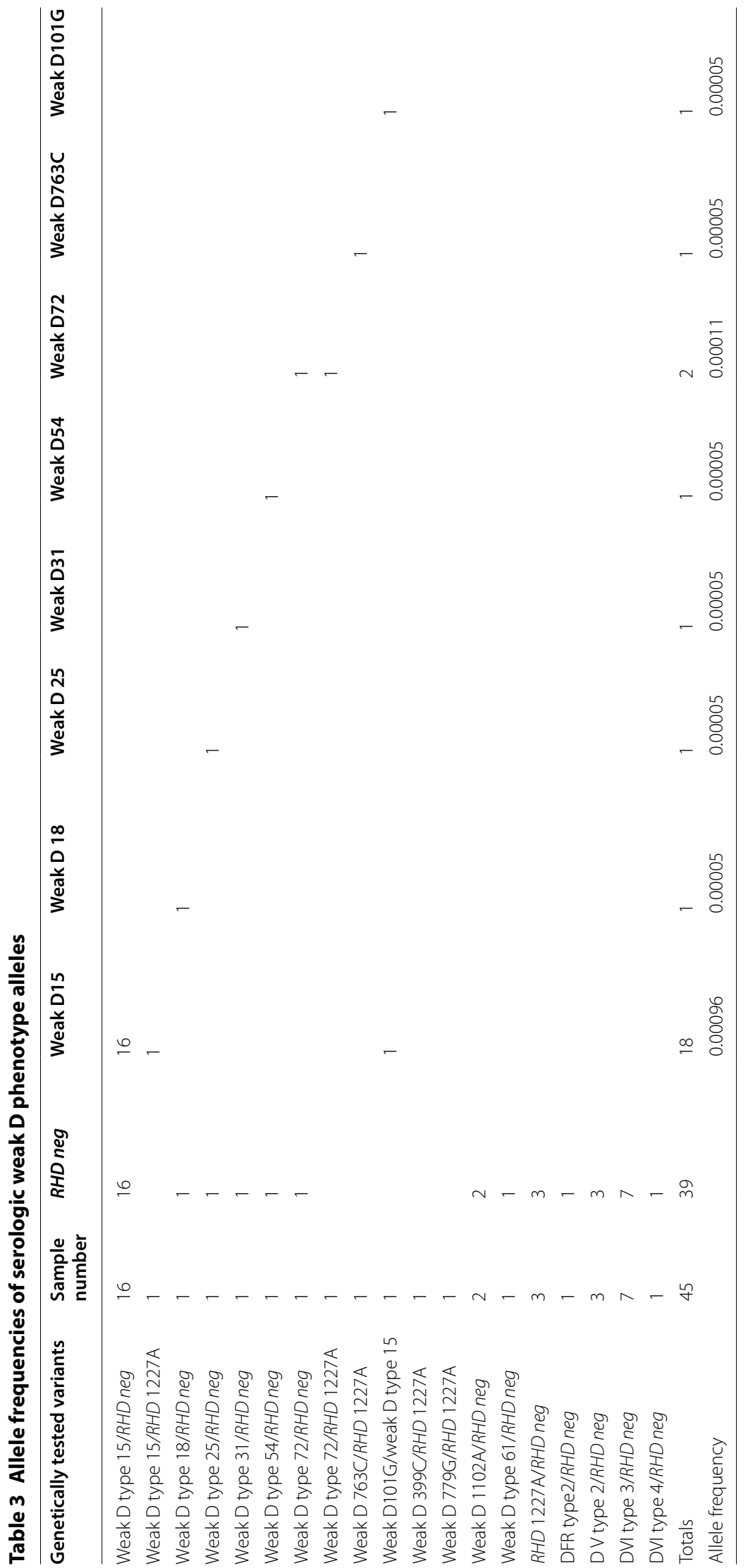


Table 4 Allele frequencies of $\mathrm{RhD}$ negative alleles

\begin{tabular}{|c|c|c|c|c|c|c|}
\hline Genetically tested RHD negative & $\begin{array}{l}\text { Sample } \\
\text { number }\end{array}$ & RHD neg & RHD 1227A & RHD 1166delA & $R H D-C e(2-9)-D$ & RHD 711delC \\
\hline RHD neg/RHD neg & 78 & 156 & & & & \\
\hline RHD neg/RHD 1227A & 24 & 24 & 24 & & & \\
\hline RHD 1227A/RHD $1227 \mathrm{~A}$ & 3 & & 6 & & & \\
\hline RHD 1227A/RHD 1166delA & 1 & & 1 & 1 & & \\
\hline RHD neg/RHD-Ce (2-9)-D & 7 & 7 & & & 7 & \\
\hline RHD-Ce (2-9)-D/RHD-Ce (2-9)-D & 2 & & & & 4 & \\
\hline RHD neg/RHD $711 \mathrm{delC}$ & 2 & 2 & & & & 2 \\
\hline Totals & 117 & 189 & 31 & 1 & 11 & 2 \\
\hline Allele frequency & & 0.04937 & 0.00810 & 0.00026 & 0.00287 & 0.00052 \\
\hline
\end{tabular}

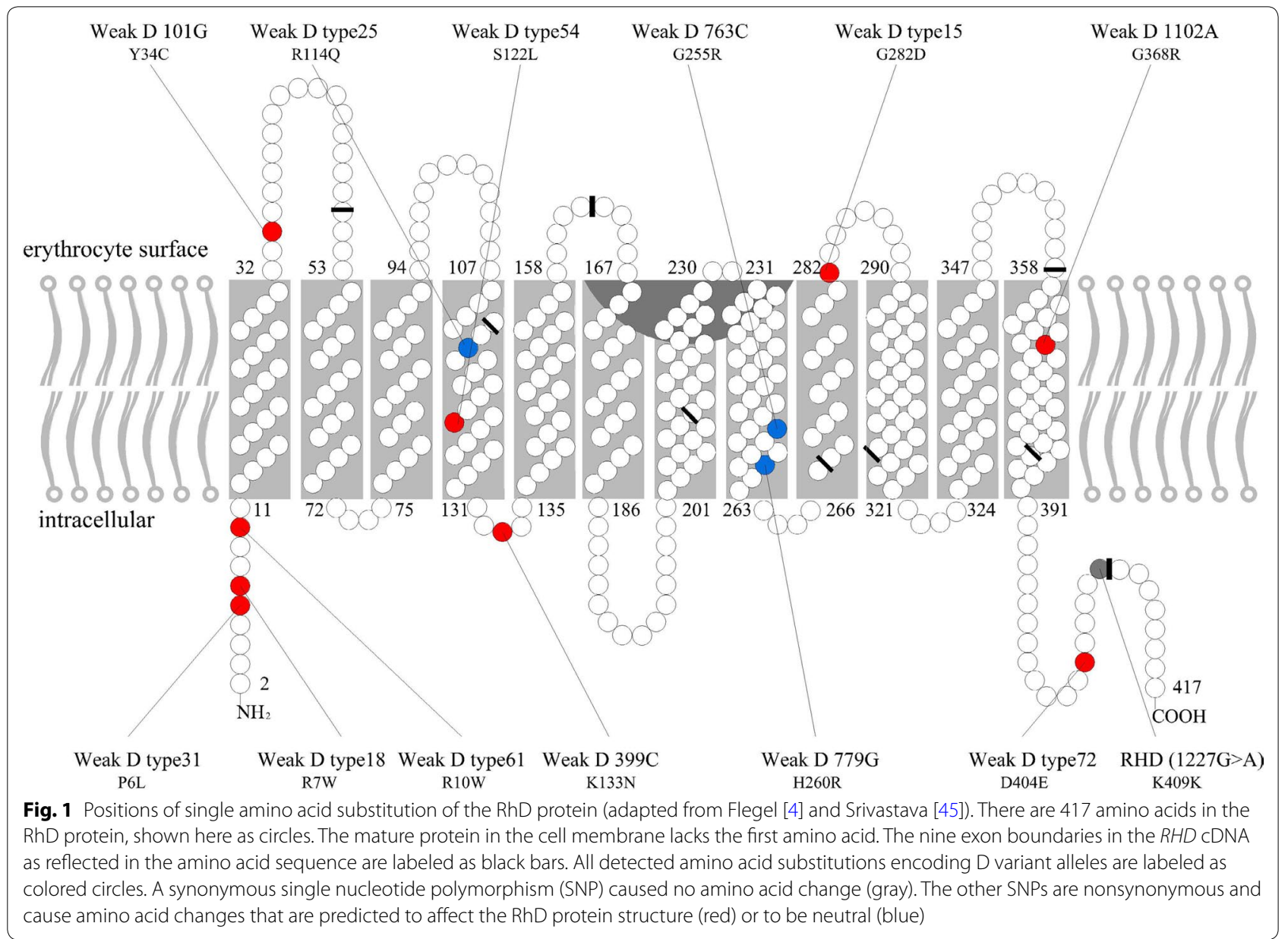

was determined on the basis of weak agglutination in the IAT procedure; it was first reported in the Chinese population [40]. The DEL (RHD1227A) variant with very low levels of $\mathrm{D}$ antigen detectable only by the adsorption-elution method accounts for $10 \%$ to $33 \%$ of apparent D negative phenotypes in eastern Asia [26, 40, 50]. As estimated, the maximum antigen site density per red cell was 36 and often no more than 22 [51]. In this study, RHD1227A was detected eight in 45 serologic weak D phenotypes and 28 in $117 \mathrm{RhD}$ negative individuals by sequencing. Primary and second immunization of $\mathrm{RhD}$ negatives by RHD1227A blood have been shown to occur $[10,11,52]$. First, as the measure for improvement of transfusion safety in China, $\mathrm{RhD}$ negative individuals should be $R H D$ genotyped, in order to reduce the number of immunizations of $\mathrm{RhD}$ negatives with RHD1227A 


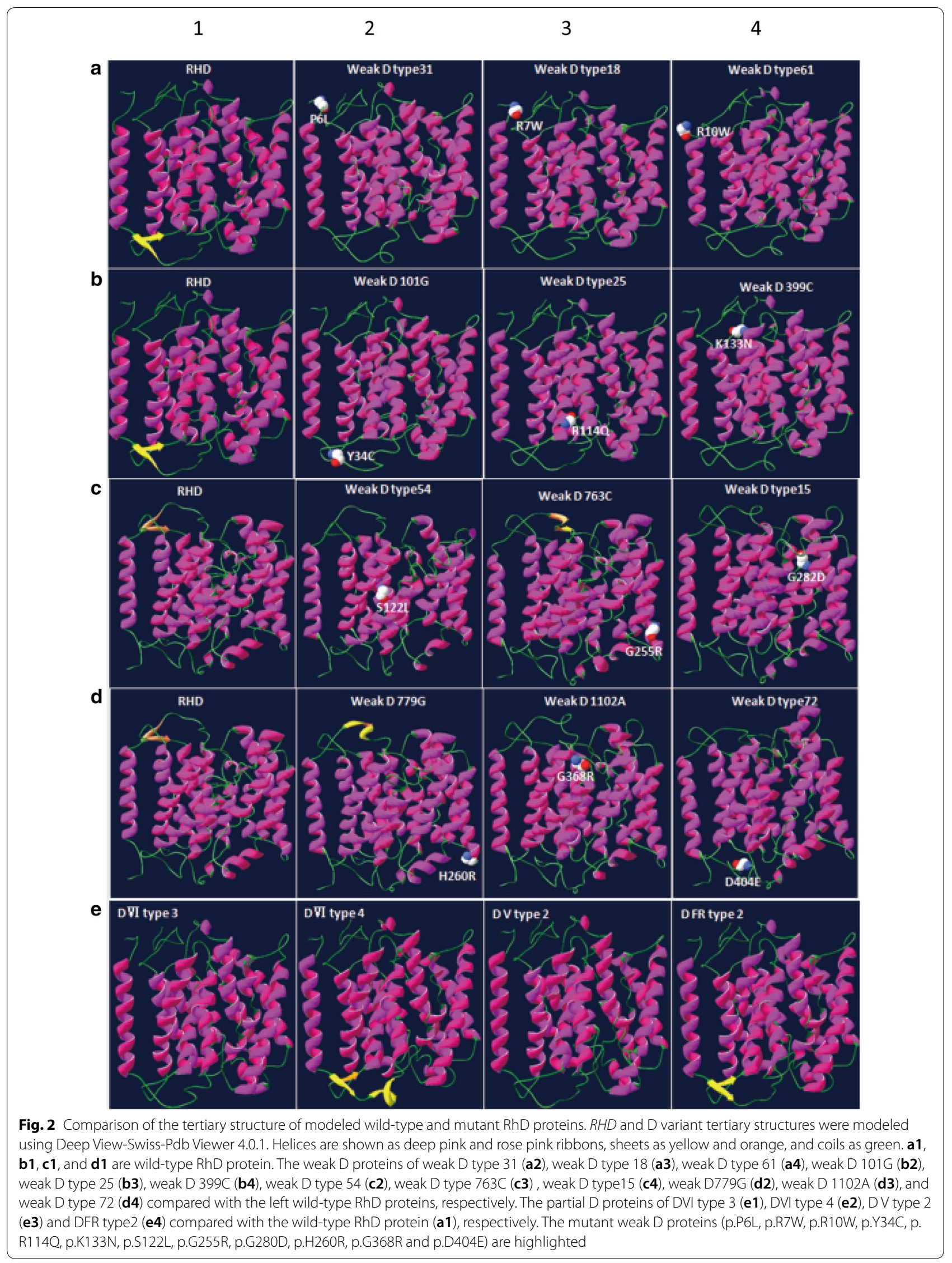


positive blood, not identified by standard serological techniques. Second, testing of "serological weak D phenotype" donors would be of interest among donors, of higher importance in recipients. For blood samples of patients or donors with serological weak D phenotype, some are hard to determine serologically. Patients with several serologic weak D phenotypes (DFR, DV, DVI, and Weak $D$ type 15) reported in this study have been found to develop alloanti-D [3]. Therefore, it is necessary to identify different $R H D$ alleles and their frequencies in different populations. More practical investigations of Rh-related transfusion and obstetrics in China and other Asian populations are encouraged.

The 12 nonsynonymous variant mutations were dispersed throughout $\mathrm{RhD}$ protein, with no clustering at specific sites. They occurred in the intracellular, exofacial, and transmembraneous red blood cell membrane (Fig. 1). While weak D phenotypes derived mainly from amino acid substitutions in intracellular or transmembrane segments of RHD, partial D is located in extracellular portions of the $R H D$ polypeptide [11, 35]. In this study, 12 weak $D$ mutations were found in the intracellular and transmembrane region, except weak D101G (c.101 A>G) [25]. The possible reason is that the precise locations of the amino acid residues of $\mathrm{RhD}$ protein in the membrane is not yet clear; different models may predict the different locations of some amino acids [3].The substitutions may also affect the tertiary interactions and stabilization of the $\mathrm{RhD}$ protein. The prediction of 3D structures showed that the space conformation of the protein was disrupted in 16 serologic weak $\mathrm{D}$ phenotypes. These all affect the normal assembly of the tertiary structure, resulting in an activity change of the $\mathrm{D}$ antigen. These results indicate that bioinformatics analysis on $\mathrm{RhD}$ protein can give us more interpretation of missense variants of $R H D$ gene.

The $R H D$ gene coding region, splicing sites, partial introns, and $5^{\prime}$ and $3^{\prime}$ UTRs were detected in 45 samples with serologic weak D phenotypes in this study. The mutation sites of the 45 samples were all located in the coding region. At present, most studies on the serologic weak D phenotype are at the DNA level, and relevant available RNA information is not comprehensive. Therefore, the molecular mechanism(s) underlying serologic weak D phenotypes need to be further investigated. In addition, due to the relative scarcity of $\mathrm{RhD}$ negative samples in the Chinese population, especially that of serologic weak D phenotype samples, data about the overall characteristics of various ethnic groups in China are still relatively lacking at the present time. Therefore, increased specimen collection is an urgent problem that remains unresolved.

\section{Conclusions}

This study describes two novel and 15 rare $R H D$ alleles by variant screening of large doubtful $D$ phenotypes and provides a brief overview of serologic weak D phenotypes with respect to their underlying mutational mechanisms. We also applied bioinformatics analysis to predicted deleterious structural changes of serologic weak D phenotypes. These data extend our knowledge of serologic weak D phenotypes in blood donors and clinical transfusion recipients, which underlies the safety of blood transfusion and which may reduce the risk of anti-D immunization.

\section{Supplementary information}

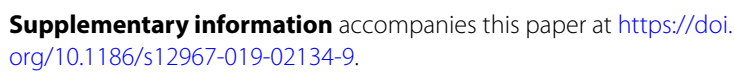

Additional file 1: Table S1. The calculation of allele frequencies for serologic weak D phenotype and RhD negative alleles.

Additional file 2: Table S2. Predicted effects on RhD protein function based on SNP missense mutations.

Additional file 3: Table S3. Predicted 3D structure of 16 serologic weak D phenotypes with the amino acid position shifts in the intracellular loop, transmembraneous domain and exofacial loop.

\section{Abbreviations}

IAT: an indirect antiglobulin test; UTRs: untranslated regions; SNP: single nucleotide polymorphism; 3D: three-dimensional; SIFT: Sorting Intolerant From Tolerant; PolyPhen-2: Polymorphism Phenotypingv2; PROVEAN: protein Variation Effect Analyzer.

\section{Acknowledgements}

We acknowledge the contributions of Prof. Yujie Zhao of the China Medical University for his technical assistance with bioinformatics and blood donors for providing samples and histories.

\section{Authors' contributions}

$X Z, H F$, and $J L$ designed the experiments. $X Z, G L, Z Z, X H$, and $L L$ carried out the experiments. XZ wrote the manuscript. $\mathrm{HF}$ and $J L$ supervised the project. $X Z, G L, C S$, and $Y L$ analyzed the data, $Z Z, X H, L L$, and $X L$ collected the samples. All authors provided critical comments and editorial modifications. All authors read and approved the final manuscript.

\section{Funding}

This work was supported by Shenyang Science and Technology Foundation (F10-206-1-00; 18-014-4-50).

\section{Availability of data and materials}

Not applicable.

\section{Ethics approval and consent to participate \\ The study was approved by the Ethics Committee of the Liaoning Blood Center, Liaoning, China.}

\section{Consent for publication}

Not applicable.

\section{Competing interests}

The authors declare that they have no competing interests. 


\section{Author details}

${ }^{1}$ Institute of Transfusion Medicine, Liaoning Blood Center, Shenyang, Liaoning, China. ${ }^{2}$ Key Laboratory of Blood Safety Research of Liaoning Province, Shenyang, Liaoning, China. ${ }^{3}$ Department of Hematology, The Forth Affiliated Hospital of China Medical University, Shenyang, Liaoning, China. ${ }^{4}$ Department of Transfusion, the Second People's Hospital of Shenzhen, Shenzhen, China. ${ }^{5}$ Institute of Transfusion Medicine, Harbin Blood Center, Harbin, Heilongjiang, China. ${ }^{6}$ Department of Pharmacology, School of Pharmacy, China Medical University, Shenyang, Liaoning, China.

Received: 8 May 2019 Accepted: 9 November 2019

\section{Published online: 27 November 2019}

\section{References}

1. Storry JR, Clausen FB, Castilho L, Chen Q, Daniels G, Denomme G, Flegel WA, Gassner C, de Haas M, Hyland C, et al. International society of blood transfusion working party on red cell immunogenetics and blood group terminology: report of the Dubai. Copenhagen and Toronto meetings. Vox Sang. 2019;114:95-102.

2. Fichou Y, Parchure D, Gogri H, Gopalkrishnan V, Le Maréchal C, Chen J-M, Férec C, Madkaikar M, Ghosh K, Kulkarni S. Molecular basis of weak D expression in the Indian population and report of a novel, predominant variant RHD allele. Transfusion. 2018;58:1540-9.

3. Daniels G. Variants of RhD-current testing and clinical consequences. Br J Haematol. 2013;161:461-70.

4. Flegel WA. Molecular genetics and clinical applications for RH. Transfus Apher Sci. 2011;44:81-91.

5. Sandler SG, Flegel WA, Westhoff CM, Denomme GA, Delaney M, Keller MA, Johnson ST, Katz L, Queenan JT, Vassallo RR, Simon CD. It's time to phase in RHD genotyping for patients with a serologic weak D phenotype. College of American Pathologists Transfusion Medicine Resource Committee Work Group. Transfusion. 2015;55:680-9.

6. Sandler SG, Chen LN, Flegel WA. Serological weak D phenotypes: a review and guidance for interpreting the RhD blood type using the RHD genotype. Br J Haematol. 2017;179:10-9.

7. Stegmann TC, Veldhuisen B, Bijman R, Thurik FF, Bossers B, Cheroutre G, Jonkers R, Ligthart P, de Haas M, Haer-Wigman L, van der Schoot CE. Frequency and characterization of known and novel RHD variant alleles in 37 782 Dutch D-negative pregnant women. Br J Haematol. 2016;173:469-79.

8. Flegel WA, Khull SR, Wagner FF. Primary anti-D immunization by weak D type 2 RBCs. Transfusion. 2000;40:428-34.

9. Yazer $\mathrm{MH}$, Triulzi DJ. Detection of anti-D in D-recipients transfused with D + red blood cells. Transfusion. 2007;47:2197-201.

10. Kim KH, Kim KE, Woo KS, Han JY, Kim JM, Park KU. Primary anti-D immunization by DEL red blood cells. Korean J Lab Med. 2009;29:361-5.

11. Sandler SG, Flegel WA. Does transfusion of Asian-type DEL red blood cells to D- recipients cause D alloimmunization? Transfusion. 2019;59:2455-8.

12. Wagner FF, Flegel WA. The Rhesus Site. Transfus Med Hemother. 2014;41:357-63.

13. Patnaik SK, Helmberg W, Blumenfeld OO. BGMUT: NCBI dbRBC database of allelic variations of genes encoding antigens of blood group systems. Nucleic Acids Res. 2012;40:D1023-9.

14. Storry JR, Castilho L, Daniels G, Flegel WA, Garratty G, de Haas M, Hyland C, Lomas-Francis C, Moulds JM, Nogues N, et al. International Society of Blood Transfusion Working Party on red cell immunogenetics and blood group terminology: cancun report (2012). Vox Sang. 2014;107:90-6.

15. Fichou Y, Le Marechal C, Bryckaert L, Guerry C, Benech C, Dupont I, Jamet D, Ferec C, Chen JM. Variant screening of the RHD gene in a large cohort of subjects with $D$ phenotype ambiguity: report of 17 novel rare alleles. Transfusion. 2012;52:759-64.

16. Van Sandt VS, Gassner C, Emonds MP, Legler TJ, Mahieu S, Kormoczi GF. RHD variants in Flanders, Belgium. Transfusion. 2015;55:1411-7.

17. Fichou Y, Le Marechal C, Jamet D, Bryckaert L, Ka C, Audrezet MP, Le Gac G, Dupont I, Chen JM, Ferec C. Establishment of a medium-throughput approach for the genotyping of RHD variants and report of nine novel rare alleles. Transfusion. 2013;53:1821-8.

18. McGowan EC, Lopez GH, Knauth CM, Liew YW, Condon JA, Ramadi L, Parsons K, Turner EM, Flower RL, Hyland CA. Diverse and novel RHD variants in Australian blood donors with a weak D phenotype: implication for transfusion management. Vox Sang. 2017;112:279-87.

19. Silvy M, Simon S, Gouvitsos J, Di Cristofaro J, Ferrera V, Chiaroni J, Bailly P. Weak D and DEL alleles detected by routine SNaPshot genotyping: identification of four novel RHD alleles. Transfusion. 2011;51:401-11.

20. Denomme GA, Wagner FF, Fernandes BJ, Li W, Flegel WA. Partial D, weak D types, and novel RHD alleles among 33,864 multiethnic patients: implications for anti-D alloimmunization and prevention. Transfusion. 2005;45:1554-60.

21. Chen Q, Flegel WA. Random survey for RHD alleles among D + European persons. Transfusion. 2005;45:1183-91.

22. Ouchari M, Jemni-Yaacoub S, Chakroun T, Abdelkefi S, Houissa B, Hmida S RHD alleles in the Tunisian population. Asian J Transfus Sci. 2013;7:119-24.

23. Ba A, Beley S, Chiaroni J, Bailly P, Silvy M. RH diversity in Mali: characterization of a new haplotype RHD*DIVa/RHCE* CeTI(D2). Transfusion. 2015;55:1423-31.

24. Yan L, Wu J, Zhu F, Hong X, Xu X. Molecular basis of D variants in Chinese persons. Transfusion. 2007;47:471-7.

25. He J, Ying Y, Hong X, Xu X, Zhu F, Lv H. Molecular basis and zygosity determination of $D$ variants including identification of four novel alleles in Chinese individuals. Transfusion. 2015;55:137-43.

26. Shao CP, Maas JH, Su YQ, Köhler M, Legler TJ. Molecular background of Rh D-positive, D-negative, Del and weak D phenotypes in Chinese. Vox Sang 2002;83:156-61.

27. Ye L, Wang P, Gao H, Zhang J, Wang C, Li Q, Han S, Guo Z, Yang Y, Zhu Z. Partial D phenotypes and genotypes in the Chinese population. Transfusion. 2012;52:241-6.

28. Ji YL, Luo H, Wen JZ, Haer-Wigman L, Veldhuisen B, Wei L, Wang Z, Ligthart P, Loden-van Straaten M, Fu YS, et al. RHD genotype and zygosity analysis in the Chinese Southern Han D+, D- and D variant donors using the multiplex ligation-dependent probe amplification assay. Vox Sang. 2017;112:660-70.

29. Perco P, Shao CP, Mayr WR, Panzer S, Legler TJ. Testing for the D zygosity with three different methods revealed altered Rhesus boxes and a new weak D type. Transfusion. 2003;43:335-9.

30. Kalia N, Sharma A, Kaur M, Kamboj SS, Singh J. A comprehensive in silico analysis of non-synonymous and regulatory SNPs of human MBL2 gene. Springerplus. 2016:5:811.

31. Johansson MU, Zoete V, Michielin O, Guex N. Defining and searching for structural motifs using DeepView/Swiss-PdbViewer. BMC Bioinform. 2012;13:173.

32. Ng PC, Henikoff S. Predicting deleterious amino acid substitutions. Genome Res. 2001;11:863-74.

33. Adzhubei IA, Schmidt S, Peshkin L, Ramensky VE, Gerasimova A, Bork P, Kondrashov AS, Sunyaev SR. A method and server for predicting damaging missense mutations. Nat Methods. 2010;7:248-9.

34. Choi Y, Sims GE, Murphy S, Miller JR, Chan AP. Predicting the functional effect of amino acid substitutions and indels. PLoS ONE. 2012;7:e46688.

35. Wagner FF, Gassner C, Müller TH, Schönitzer D, Schunter F, Flegel WA. Molecular basis of weak D phenotypes. Blood. 1999;93:385-93.

36. Wagner FF, Frohmajer A, Flegel WA. RHD positive haplotypes in D negative Europeans. BMC Genet. 2001;2:10.

37. Arnoni CP, Latini FR, Muniz JG, Gazito D, Person RD, Vendrame TA, Barreto JA, Castilho L. How do we identify RHD variants using a practical molecular approach? Transfusion. 2014;54(4):962-9.

38. Schmid P, von Zabern I, Scharberg EA, Wagner FF, Flegel WA. Specific amino acid substitutions cause distinct expression of JAL (RH48) and JAHK (RH53) antigens in RhCE and not in RhD. Transfusion. 2010;50:267-9.

39. Kormoczi GF, Forstemann E, Gabriel C, Mayr WR, Schonitzer D, Gassner C. Novel weak D types 31 and 32: adsorption-elution-supported D antigen analysis and comparison to prevalent weak D types. Transfusion. 2005;45:1574-80

40. Li Q, Hou L, Guo ZH, Ye LY, Yue DQ, Zhu ZY. Molecular basis of the RHD gene in blood donors with DEL phenotypes in Shanghai. Vox Sang. 2009;97:139-46.

41. Fichou Y, Parchure D, Gogri H, Gopalkrishnan V, Le Maréchal C, Chen J-M, Férec C, Madkaikar M, Ghosh K, Kulkarni S. Molecular basis of weak D expression in the Indian population and report of a novel, predominant variant RHD allele. Transfusion. 2018;58:1540-9.

42. Rouillac C, Colin Y, Hughes-Jones NC, Beolet M, D'Ambrosio AM, Cartron $J$, Le Van Kim C. Transcript analysis of D category phenotypes predicts 
hybrid Rh D-CE-D proteins associated with alteration of D epitopes. Blood. 1995:85:2937-44.

43. Wagner FF, Gassner C, Muller TH, Schonitzer D, Schunter F, Flegel WA. Three molecular structures cause rhesus D category VI phenotypes with distinct immunohematologic features. Blood. 1998;91:2157-68.

44. Esteban R, Montero R, Flegel WA, Wagner FF, Subirana L, Parra R, Ribera A, Nogués N. The D category VI type 4 allele is prevalent in the Spanish population. Transfusion. 2006;46:616-23.

45. Srivastava K, Polin H, Sheldon SL, Wagner FF, Grabmer C, Gabriel C, Denomme GA, Flegel WA. The DAU cluster: a comparative analysis of 18 RHD alleles, some forming partial D antigens. Transfusion. 2016;56:2520-31.

46. Chérif-Zahar B, Bloy C, Le Van Kim C, Blanchard D, Bailly P, Hermand P, Salmon C, Cartron JP, Colin Y. Molecular cloning and protein structure of a human blood group Rh polypeptide. Proc Natl Acad Sci USA. 1990;87:6243-7.

47. Luettringhaus TA, Cho D, Ryang DW, Flegel WA. An easy RHD genotyping strategy for D- East Asian persons applied to Korean blood donors. Transfusion. 2006;46:2128-37.

48. Ogasawara K, Sasaki K, Isa K, Tsuneyama H, Uchikawa M, Satake M, Tadokoro K. Weak D alleles in Japanese: a C960G > A silent mutation in exon 7 of the RHD gene that affects D expression. Vox Sang. 2016;110:179-84.
49. Liu HC, Eng HL, Yang YF, Wang YH, Lin KT, Wu HL, Lin TM. Aberrant RNA splicing in RHD 7-9 exons of DEL individuals in Taiwan: a mechanism study. Biochim Biophys Acta. 2010;1800:565-73.

50. Okuda H, Kawano M, Iwamoto S, Tanaka M, Seno T, Okubo Y, Kajii E. The RHD gene is highly detectable in RhD-negative Japanese donors. J Clin Invest. 1997;100:373-9.

51. Kormoczi GF, Gassner C, Shao CP, Uchikawa M, Legler TJ. A comprehensive analysis of DEL types: partial DEL individuals are prone to anti-D alloimmunization. Transfusion. 2005;45:1561-7.

52. Yasuda H, Ohto H, Sakuma S, Ishikawa Y. Secondary anti-D immunization by Del red blood cells. Transfusion. 2005;45:1581-4.

\section{Publisher's Note}

Springer Nature remains neutral with regard to jurisdictional claims in published maps and institutional affiliations.
Ready to submit your research? Choose BMC and benefit from:

- fast, convenient online submission

- thorough peer review by experienced researchers in your field

- rapid publication on acceptance

- support for research data, including large and complex data types

- gold Open Access which fosters wider collaboration and increased citations

- maximum visibility for your research: over $100 \mathrm{M}$ website views per year

At BMC, research is always in progress.

Learn more biomedcentral.com/submissions 